Article

\title{
Iodine and Mercury Content in Raw, Boiled, Pan-Fried, and Oven-Baked Atlantic Cod (Gadus morhua)
}

\author{
Lisbeth Dahl *(D), Arne Duinker® ${ }^{\circledR}$, Synnøve Næss ${ }^{\circledR}$, Maria Wik Markhus, Ive Nerhus, \\ Lisa Kolden Midtbø and Marian Kjellevold $D$ \\ Department of Seafood and Nutrition, Institute of Marine Research (IMR), NO-5817 Bergen, Norway; \\ Arne.Duinker@hi.no (A.D.); synnoeve.naess@hi.no (S.N.); Maria.Wik.Markhus@hi.no (M.W.M.); \\ i.nerhus@gmail.com (I.N.); Lisa.Kolden.Midtbo@moreforsk.no (L.K.M.); Marian.Kjellevold@hi.no (M.K.) \\ * Correspondence: Lisbeth.Dahl@hi.no; Tel.: +47-472-91-689
}

Received: 2 October 2020; Accepted: 9 November 2020; Published: 12 November 2020

\begin{abstract}
There is a lack of scientific evidence regarding the stability of iodine and mercury during cooking and processing of seafood. In this study, the iodine and mercury content were determined after thawing frozen fillets of Atlantic cod (Cadus morhua), and further in raw compared to boiled, pan-fried, and oven baked fillets. Iodine was determined by Inductively Coupled Plasma-Mass Spectrometry (ICP-MS) and mercury by atomic absorption spectrophotometry with Direct Mercury Analyzer (DMA-80). Thawing of the cod resulted on average in a $12 \%$ loss of iodine to the thawing water. Boiling significantly decreased the total content of iodine per slice of cod fillet corresponding to the concentration of iodine found in the boiling water. Pan-frying and oven-baking did not cause any significant changes of the total iodine content per slice of cod fillet, although iodine content per $100 \mathrm{~g}$ increased due to weight reduction of the cod slices from evaporation of water during preparation. For mercury, we found minimal changes of the different cooking methods. In summary, the findings in our study show that boiling had the greatest effect on the iodine content in the cod fillets. Type of cooking method should be specified in food composition databases as this in turn may influence estimation of iodine intake.
\end{abstract}

Keywords: fish; cooking; processing; food composition data; analysis; ICP-MS; DMA-80; nutrition security

\section{Introduction}

Representative, local, up-to date high-quality food composition data are of fundamental importance for estimating nutrient intake in a population. Chemical analysis is the gold standard for generating data, but due to costs, analytical data comprise only a minor part of available information in most food composition databases (FCDB) and in food composition tables (FCT) [1]. Changes in nutrient content due to cooking method; for instance, boiling, frying, and grilling, and processing such as smoking, salting, and drying, should be considered when estimating nutrient intake of different foods [2]. Storage of fish by freezing is an often-used method to increase the shelf life of seafood. Thus, any changes of nutrient content during thawing, and further use of processing and cooking methods of the fish is important to quantify.

Presently, the Norwegian FCT [3] and the International Network of Food Data Systems (INFOODS) Food composition database (FCDB) [4] for fish and shellfish [5] only include analytical data on iodine in raw fish. In both the INFOODS FCDB [4] and the Norwegian FCT [3], values for cooked, fried, and processed fish are estimated or calculated, not chemically analyzed. Analytical data on 
contaminants and heavy metals are not included in the Norwegian FCT, but such data in seafood are available in the open access Seafood database [6] at Institute of Marine Research (IMR). Atlantic cod (Gadus morhua) is the most commonly consumed lean white fish species in Norway, and total catch was 327,648 tons (live weight) in the Norwegian fisheries in 2019 [7]. Raw Atlantic cod and other lean fish species such as pollack (Pollachius pollachius), haddock (Melanogrammus aeglefinus), and saithe (Pollachius virens) have a considerably higher content of iodine than fatty fish species like mackerel (Scomber scombrus), herring (Clupea harengus), and farmed Atlantic salmon (Salmo salar) [8,9]. Iodine is an essential micronutrient for humans and has an important role in growth, brain development, and metabolism as it is active in the biosynthesis of thyroid hormones [10]. At the same time, the range for acceptable iodine intake for adults is from 150 to $600 \mu \mathrm{g} /$ day and is considered relatively constricted compared to other micronutrients [11]. Thus, it is important to have high quality data on iodine in iodine rich foods such as Atlantic cod. However, Atlantic cod is also a source of mercury and methylmercury. This is of concern in relation to food safety, as humans are predominantly exposed to mercury through fish consumption [12]. The content of mercury in different fish species varies considerably and depends on factors such as type of species, geographical area, size, and age [13]. Knowledge about mercury exposure in humans is of importance as mercury in the form of methylmercury may have adverse effects such as impaired neurodevelopment of the fetus during pregnancy [14]. We have previously published analytical data on iodine and mercury in several raw lean fish species $[13,15,16]$ and in processed fish products $[17,18]$. In the present study, the main aim was to analyze the total iodine and mercury content in Atlantic cod fillets after thawing and further after three different cooking methods, i.e., boiling, pan-frying, and oven-baking. To our knowledge, this is the first experiment presenting analytical data on iodine and mercury content in Atlantic cod during different cooking methods.

\section{Materials and Methods}

\subsection{Fish Samples}

The study included Atlantic cod (Gadus morhua) catched in the Barents Sea in October 2015 purchased from Lerøy Seafood Group ASA (bought after tender). The cod weight ranged from $1-2.5 \mathrm{~kg}$ and was immediately frozen in blocks of $25 \mathrm{~kg}$, and stored as whole fish without the head and organs at $-30^{\circ} \mathrm{C}$. In December 2015, the cod was thawed and fillet portions of approximately $200 \mathrm{~g}$ without skin were produced and frozen separately in strings of four fillets in each package (Bulandet Fiskeindustri AS, Lerøy Seafood Group ASA) before transported frozen to the IMR and stored in an outdoor freezing room at $-30{ }^{\circ} \mathrm{C}$ pending analysis and delivery to participants in the randomized intervention study "Mommy food" [19].

\subsection{Practical Procedure and Sample Preparation}

The cod fillet packages were thawed overnight for approximately $18 \mathrm{~h}$ in a refrigerator at $4{ }^{\circ} \mathrm{C}$ before the experiment was performed in July 2017. In total, 30 cod fillets were used in the present study. Each fillet was divided into two portions of approximately $100 \mathrm{~g}$ each. Half of each cod portion of $100 \mathrm{~g}$ was kept raw $(n=30)$. The other half was further prepared for three different cooking methods either 1: boiled $(n=10), 2$ : pan-fried $(n=10)$, or 3: oven-baked $(n=10)$. All cod fillets were weighted before and after processing. Figure 1 shows a schematic overview of the sample preparation of the cod fillets. 


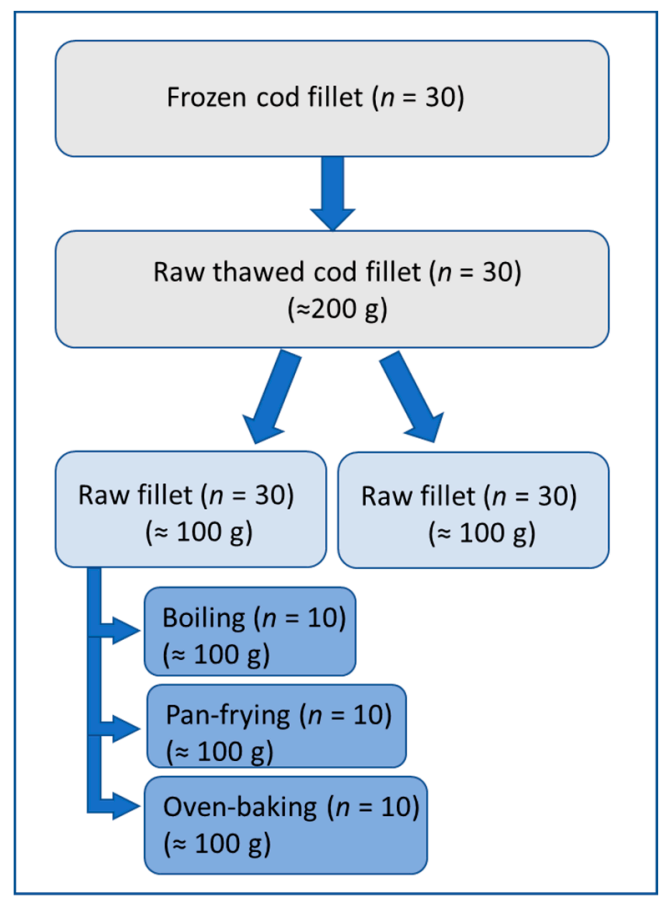

Figure 1. Schematic overview of cod fillet processing.

For cooking method 1, boiling, each cod fillet of approximately $100 \mathrm{~g}$ was put into a pan of boiling water and then stirred for $10 \mathrm{~min}$ in $1 \mathrm{~L}$ of water. For cooking method 2, pan-frying, the cod fillets were pan-fried for 6-7 minutes in $10 \mathrm{~mL}$ of rapeseed oil at medium temperature. For cooking method 3 , oven-baking, the cod fillets were baked in the oven at $180^{\circ} \mathrm{C}$ for $15 \mathrm{~min}$. Thawing- and boiling water and any liquid left after pan-frying or oven baking were also collected for analyses of iodine. The experiment was performed using a household ceramic electric cooker (Gorenje, SuperPower Induction), a stainless-steel cooking pan ( $3 \mathrm{~L}$ of size), aluminum frying pan covered with Teflon (diameter $28 \mathrm{~cm}$ ), and disposable aluminum form ( $0.5 \mathrm{~L}$ of size). No salt, spices, or food additives were used in the different cooking procedures.

After the experiment, all cod samples were freeze-dried (Labconco Freezone 18L Mod.775030, Kansas City, MI, USA) to constant weight using an accredited method according to ISO 17025. The samples were homogenized, and a sub-sample of the wet sample were weighed individually, put in separate plastic containers and frozen at minus $20^{\circ} \mathrm{C}$ overnight. The samples were freeze-dried for $72 \mathrm{~h}\left(24 \mathrm{~h}\right.$ at $-50{ }^{\circ} \mathrm{C}$, immediately followed by $48 \mathrm{~h}$ at $+25^{\circ} \mathrm{C}$, with a vacuum of $\left.0.2-0.01 \mathrm{mbar}\right)$. The samples were then weighed once again, and the dry matter was calculated based on the difference in weight of the sample before and after freeze-drying. The method is validated, and measurement uncertainty is $10 \%$ for dry weight samples in the range of $>10$ to $99.5 \mathrm{~g} / 100 \mathrm{~g}$. Freeze-dried samples were then homogenized to a fine powder using a domestic mill and stored in twist off boxes at room temperature pending analysis. In total, 60 samples of cod $(\operatorname{raw}(n=30)$ and processed $(n=30))$ and 60 samples of liquid (i.e., thawing water $(n=30)$, boiling water $(n=10)$, liquid after pan-frying $(n=10)$, and oven baking $(n=10))$ were collected. Iodine was determined in all samples $(n=120)$ and mercury was determined only in the cod fillet samples $(n=60)$, i.e., not in the liquid samples. To evaluate if the different cooking methods had any effect on iodine and mercury, we assessed the iodine and mercury content $(\mu \mathrm{g})$ per piece of cod fillet and per $100 \mathrm{~g}(\mu \mathrm{g} / 100 \mathrm{~g})$ cod fillet before and after cooking.

\subsection{Determination of Iodine}

For the determination of iodine, subsamples of $\sim 0.2 \mathrm{~g}$ dry weight were added to $1 \mathrm{~mL}$ ultrapure tetrametylammonium hydroxide (TMAH) and $5 \mathrm{~mL}$ deionized water $\left(>17 \mathrm{M} \Omega \mathrm{cm}^{-1}\right.$, Nano pure-system, Nanopure, Barnstead, UK) before extraction at $90{ }^{\circ} \mathrm{C} \pm 3{ }^{\circ} \mathrm{C}$ for $3 \mathrm{~h}$. For the extraction of the liquid 
samples, $4 \mathrm{~mL}$ of liquid was added to $1 \mathrm{~mL}$ TMAH. The liquid- and the cod samples were, after extraction, diluted to $10 \mathrm{~mL}$ and $25 \mathrm{~mL}$, respectively with deionized water and left overnight for sedimentation of any solid particles. Aliquots of $10 \mathrm{~mL}$ were pipetted from the middle of the tubes in order to avoid taking up any precipitate from the bottom part of the solution. Prior to quantification, the samples were filtered through a $0.45 \mu \mathrm{m}$ single use syringe and disposal filter. The $1 \% \mathrm{TMAH}$ solution contained tellurium $(1 \mathrm{mg} / \mathrm{L})$ which was used as an internal standard in order to correct for instrument drift. Samples were analyzed against a standard addition calibration curve $(2,5,10,20$, and $50 \mu \mathrm{g} / \mathrm{L})$ to measure the unknown iodine content in the samples. Iodine was determined by Inductively Coupled Plasma-Mass Spectrometry (ICP-MS) with an iCap Q ICP-MS (Termo Fisher Scientific, Waltham, MA, USA) equipped with an autosampler (FAST SC-4Q DX, Elemental Scientific, Omaha, NE, USA). Limit of quantification (LOQ) is $0.32 \mu \mathrm{g} / \mathrm{L}$ or $0.04 \mathrm{mg} / \mathrm{kg}$ dry weight. Limit of detection (LOD) is $0.01 \mu \mathrm{g} / \mathrm{L}$. The measurement uncertainty differs depending on the concentration range and is set to $15 \%$ for concentrations $>10 \times$ LOQ and $40 \%$ for concentrations between LOQ and $10 \times$ LOQ. The trueness of the method was evaluated by analysis of Certified Reference Material (CRM). The CRM value for Fish muscle (BB 422) and skim milk powder (ERM-BD 150) is $1.4 \pm 0.40 \mathrm{mg} / \mathrm{kg}$ and $1.73 \pm 0.14 \mathrm{mg} / \mathrm{kg}$ for iodine, receptively. The trueness for iodine in CRMs used in the present study $(n=6)$ was in good agreement with the certified values and with the control chart of these two CRMs.

\subsection{Determination of Mercury}

For the determination of mercury, the cod samples were analyzed for total mercury by thermal decomposition, amalgamation, and atomic absorption spectrophotometry [20] using a Direct Mercury Analyzer (DMA-80, Milestone Srl, Italy). DMA-80 is calibrated in the linear area of mercury from $1.5-1000 \mathrm{ng}$. For samples in this area the accuracy is $80-120 \%$. Samples were weighed on a calibrated four decimal scale from Sartorius (CP124S, Goettingen, Germany) and positioned in separated nickel boats prior to analyses. There are 40 positions for metal boats per analysis series in DMA-80. For each analysis series, there were empty metals boats at position 1 and 2 to make sure of no contamination from previous analyses. TORT-3: Lobster Hepatopancreas Reference Material for Trace Metals was used as CRM. A total of six samples of TORT-3 were placed at the beginning $(n=2)$, middle $(n=2)$, and end $(n=2)$ of the analysis series to check the accuracy of the method throughout the analysis. The CRM value for TORT-3 is $292 \mu \mathrm{g} / \mathrm{kg}$ for total mercury. Mean \pm SD of analyzed CRM $(n=6)$ was $295 \pm 11.4 \mu \mathrm{g} / \mathrm{kg}$ for total mercury, giving a mean accuracy of $101 \%$ (\% relative SD: $3.9 \%$ ). All results were within the accepted area of the analyses $( \pm 20 \%)$. Mercury determination was performed in two consecutive series and all analyzed values were above the LOQ of $0.08 \mathrm{ng}$ mercury and the LOD of $0.02 \mathrm{ng}$.

\subsection{Data Analysis and Statistical Methods}

The descriptive statistics mean, standard deviation (SD) of mean, median, and range were conducted using Microsoft Office Excel 365 ProPlus (Microsoft Corporation, Redmond, WA, USA). For testing changes during cooking, percentage change from before to after cooking was used as this also normalized some of the variation from a few samples with high iodine levels. Statistica 13 (CStatsoft, Tulsa, OK, USA) was used to test if cooking methods had impact on the iodine and mercury content as well as dry weight percentages, using t-tests on percentage change, to test if these were different from zero.

\section{Results}

\subsection{Total Iodine and Mercury Content in Raw Cod Slices after Thawing}

The iodine and mercury content in thawed raw $\operatorname{cod}(n=30)(\sim 100 \mathrm{~g} /$ piece of cod fillet) and iodine in the associated thawing water are shown in Table 1 , given as total $\mu \mathrm{g}$ per piece of cod fillets or in thawing water. The mean \pm SD and median iodine content in the raw thawed cod fillets $(n=30)$ were 
$72 \pm 87 \mu \mathrm{g}$ and $52 \mu \mathrm{g}$ wet weight, respectively. The iodine content $(\mu \mathrm{g})$ ranged from $29.8 \mu \mathrm{g}$ (cod \#22) to $512.8 \mu \mathrm{g}(\operatorname{cod} \# 10)$ in the raw thawed cod fillets. Relative loss of iodine into the thawing water ranged from $5.5 \%$ (cod \#23) to $19.9 \%$ (cod \#21) with an average loss of $11.6 \pm 3.4 \%$ (Table 1 ). The sample with the highest iodine content ( $\operatorname{cod} \# 10$ ) had similar loss into the thawing water compared to the other samples with lower iodine content. The mercury content in the raw thawed cod ranged from $1.3 \mu \mathrm{g}$ (cod \#19) to $6.3 \mu \mathrm{g}$ (cod \#13) per cod fillet wet weight with a mean \pm SD and median mercury content of $2.6 \pm 1.4 \mu \mathrm{g}$ and $2.2 \mu \mathrm{g}$ wet weight per cod sample $(n=30)$, respectively.

Table 1. Total iodine and mercury $(\mu \mathrm{g})$ in raw cod fillets after thawing and iodine in thawing water ( $\mu \mathrm{g}$ and $\%$ ). Numbers are given as mean \pm SD and (median) wet weight.

\begin{tabular}{ccccc}
\hline Sample & $\begin{array}{c}\text { Iodine/Raw Fillet * } \\
(\boldsymbol{\mu g})\end{array}$ & $\begin{array}{c}\text { Iodine Thawing } \\
\text { Water }(\boldsymbol{\mu g})\end{array}$ & $\begin{array}{c}\text { Iodine Loss after } \\
\text { Thawing }(\mathbf{\%})\end{array}$ & $\begin{array}{c}\text { Mercury/Raw Fillet } \\
(\boldsymbol{\mu g})\end{array}$ \\
\hline Cod fillet $(\# 1-10)$ & $101.4 \pm 146.4$ & $13.0 \pm 19.6$ & $12.3 \pm 1.9$ & $2.7 \pm 1.3$ \\
& $(53.0)$ & $(6.0)$ & $(12.2)$ & $(2.3)$ \\
Cod fillet $(\# 11-20)$ & $59.7 \pm 32.7$ & $7.2 \pm 4.3$ & $12.2 \pm 3.1$ & $3.0 \pm 1.8$ \\
& $(50.0)$ & $(6.7)$ & $(13.3)$ & $(2.4)$ \\
Cod fillet $(\# 21-30)$ & $54.7 \pm 15.5$ & $5.2 \pm 1.8$ & $10.2 \pm 4.6$ & $2.1 \pm 0.8$ \\
& $(53.4)$ & $(4.8)$ & $(8.9)$ & $(2.0)$ \\
All $(n=30)$ & $71.9 \pm 86.7$ & $8.5 \pm 11.7$ & $11.6 \pm 3.4$ & $2.6 \pm 1.4$ \\
& $(52.0)$ & $(5.4)$ & $(11.7)$ & $(2.2)$ \\
\hline
\end{tabular}

* The other half of the cod fillets \#1-10 were boiled, \#11-20 were pan-fried, and \#21-30 were oven-baked.

\subsection{Dry Weight and Weight of the Cod Fillets before and after Different Cooking Methods}

The dry weight $(\%)$ and weight $(\mathrm{g})$ of the cod fillets before and after the different cooking methods are reported in Table 2 . The mean \pm SD dry weight in the cod fillets $(n=30)$ was $19.1 \pm 0.6 \%$ before and $23.3 \pm 2.0 \%$ after the different cooking methods. The dry weight increased significantly $(p<0.01)$, with the highest increase after pan-frying of the fillets.

Table 2. Dry weight (\%) and weight (g) of the cod fillets before and after the different cooking methods and percent change of weight in wet weight. Numbers are given as mean \pm SD and (median).

\begin{tabular}{cccccc}
\hline Cooking Method & $\begin{array}{c}\text { Dry Weight } \\
\text { before (\%) }\end{array}$ & $\begin{array}{c}\text { Dry Weight } \\
\text { after (\%) }\end{array}$ & $\begin{array}{c}\text { Weight before } \\
\text { (g) }\end{array}$ & $\begin{array}{c}\text { Weight after } \\
\text { (g) }\end{array}$ & $\begin{array}{c}\text { Weight Change } \\
(\%)\end{array}$ \\
\hline Boiling $(n=10)$ & $18.9 \pm 0.6^{\mathrm{a}}$ & $21.0 \pm 0.7^{\mathrm{b}}$ & $99.6 \pm 7.4^{\mathrm{a}}$ & $84.2 \pm 7.5^{\mathrm{b}}$ & $15.5 \pm 3.5$ \\
& $(19.0)$ & $(20.7)$ & $(99.8)$ & $(84.5)$ & $(16.6)$ \\
Pan-frying $(n=10)$ & $19.0 \pm 0.5^{\mathrm{a}}$ & $25.6 \pm 0.9^{\mathrm{b}}$ & $100.7 \pm 7.1^{\mathrm{a}}$ & $82.1 \pm 7.4^{\mathrm{b}}$ & $18.6 \pm 1.9$ \\
& $(19.0)$ & $(25.7)$ & $(100.8)$ & $(81.6)$ & $(18.0)$ \\
Oven-baking $(n=10)$ & $19.5 \pm 0.6^{\mathrm{a}}$ & $23.2 \pm 0.5^{\mathrm{b}}$ & $103.6 \pm 7.3^{\mathrm{a}}$ & $82.5 \pm 7.4^{\mathrm{b}}$ & $20.4 \pm 2.4$ \\
& $(19.4)$ & $(23.2)$ & $(100.2)$ & $(81.8)$ & $(20.0)$ \\
All $(n=30)$ & $19.1 \pm 0.6$ & $23.3 \pm 2.0$ & $101.3 \pm 7.2$ & $82.9 \pm 7.2$ & $18.2 \pm 3.3$ \\
& $(19.0)$ & $(23.2)$ & $(101.2)$ & $(20.0)$ & $(18.6)$ \\
\hline
\end{tabular}

Different letters denote significantly differences between dry weight rows and between weight rows $(p<0.01)$.

The weight of the raw cod fillet $(n=30)$ varied from $77.2 \mathrm{~g}(\operatorname{cod} \# 11)$ to $110.1 \mathrm{~g}(\operatorname{cod} \# 23)$ with a mean \pm SD weight of $101.3 \pm 7.2 \mathrm{~g}$. The weight decreased significantly $(p<0.01)$ in all fillets after the different cooking methods and the weight loss ranged from $9.1 \%$ to $24.3 \%$ with a mean \pm SD and median of $18.2 \pm 3.3 \%$ and $18.6 \%$, respectively.

\subsection{Iodine and Mercury Content per Cod Fillet and Content per $100 \mathrm{~g}$ before and after Different Cooking Methods}

The iodine content per fillet $(\mu \mathrm{g})$ and per $100 \mathrm{~g}$ fillet $(\mu \mathrm{g} / 100 \mathrm{~g})$ before and after boiling, pan-frying, and oven-baking the cod fillets are shown in Table 3. Boiling the cod fillets $(n=10)$ in one liter of water reduced the iodine content per fillet with approximately $20 \%$, but was not significant. The mean \pm SD iodine concentration in the boiling water was $32 \pm 43 \mu \mathrm{g}$ and corresponded to an approximately 
$30 \%$ loss of iodine to the boiling water. The iodine content given as per $100 \mathrm{~g}$ fillet was significantly decreased by approximately $10 \%$. Pan-frying and oven-baking did not cause any significant changes to the total iodine per fillet, although iodine content per $100 \mathrm{~g}$ increased due to weight reduction of the cod slices from evaporation of water during preparation. Figure 2 shows the percentage change of iodine given as total iodine content per fillet $(\mu \mathrm{g})$ and as iodine content per $100 \mathrm{~g}(\mu \mathrm{g} / 100 \mathrm{~g})$ before and after the different cooking methods.

Table 3. Total iodine $(\mu \mathrm{g})$ per piece of cod fillets and in the associated liquid $(\mu \mathrm{g})$, and iodine content $(\mu \mathrm{g} / 100 \mathrm{~g})$ in cod fillets before and after the different cooking methods. Numbers are given as mean $\pm \mathrm{SD}$ and (median) wet weight.

\begin{tabular}{|c|c|c|c|c|c|}
\hline Cooking Method & $\begin{array}{c}\text { Iodine/Fillet, } \\
\text { before } \\
\text { ( } \mu \mathrm{g})\end{array}$ & $\begin{array}{l}\text { Iodine/Fillet, } \\
\text { after } \\
(\mu \mathrm{g})\end{array}$ & $\begin{array}{c}\text { Iodine Liquid } \\
(\mu * * \\
(\mu \mathrm{g})\end{array}$ & $\begin{array}{c}\text { Iodine Content } \\
\text { before } \\
(\mu \mathrm{g} / 100 \mathrm{~g})\end{array}$ & $\begin{array}{c}\text { Iodine } \\
\text { Content after } \\
(\mu \mathrm{g} / 100 \mathrm{~g})\end{array}$ \\
\hline Boiling $(n=10)$ & $\begin{array}{c}114.6 \pm 175.1^{a} \\
(55.3)\end{array}$ & $\begin{array}{c}79.4 \pm 101.9^{b} \\
(40.5)\end{array}$ & $\begin{array}{c}32.5 \pm 43.4 \\
\quad(14.8)\end{array}$ & $\begin{array}{c}116.9 \pm 182^{a} \\
(56)\end{array}$ & $\begin{array}{c}97.6 \pm 130.8^{a} \\
(44.5)\end{array}$ \\
\hline Pan-frying $(n=10)$ & $\begin{array}{c}65.9 \pm 29.1 \\
(56.2)\end{array}$ & $\begin{array}{c}63.9 \pm 30.4 \\
(49.5)\end{array}$ & $\begin{array}{c}1.3 \pm 0.5 \\
(1.2)\end{array}$ & $\begin{array}{c}66.7 \pm 33.8^{a} \\
(57)\end{array}$ & $\begin{array}{c}79.5 \pm 43.9^{b} \\
(62.5)\end{array}$ \\
\hline Oven-baking $(n=10)$ & $\begin{array}{c}61.6 \pm 18.1 \\
(62.4)\end{array}$ & $\begin{array}{c}55.7 \pm 15.4 \\
(57)\end{array}$ & $\begin{array}{c}9.3 \pm 3.4 \\
(16.6)\end{array}$ & $\begin{array}{c}59.1 \pm 15.6^{a} \\
(60.5)\end{array}$ & $\begin{array}{c}67.2 \pm 16.4^{b} \\
(70)\end{array}$ \\
\hline All $(n=30)$ & $\begin{array}{c}80.7 \pm 102.4 \\
(57.6)\end{array}$ & $\begin{array}{c}66.3 \pm 60.7 \\
(49.4)\end{array}$ & $\begin{array}{c}14.4 \pm 27.8 \\
(9.6)\end{array}$ & $\begin{array}{c}80.9 \pm 106.7 \\
(56.5)\end{array}$ & $\begin{array}{c}81.4 \pm 78.5 \\
(62.5)\end{array}$ \\
\hline
\end{tabular}

* Iodine was calculated by multiplying the analyzed iodine concentration in the raw cod slice with the weight of the cod slice before cooking. ${ }^{* *}$ Iodine was calculated by multiplying the analyzed iodine concentration after cooking with the weight of the cod slice after cooking. Different letters denote significant differences between rows $p=0.001$. *** Iodine in liquid (\%) was calculated by dividing analyzed iodine concentration in the liquid with analyzed iodine content in the raw cod slice and then dividing by 100 . Different letters denote significant differences between iodine per fillet rows and between iodine content per $100 \mathrm{~g}$ fillet rows $(p<0.01)$.

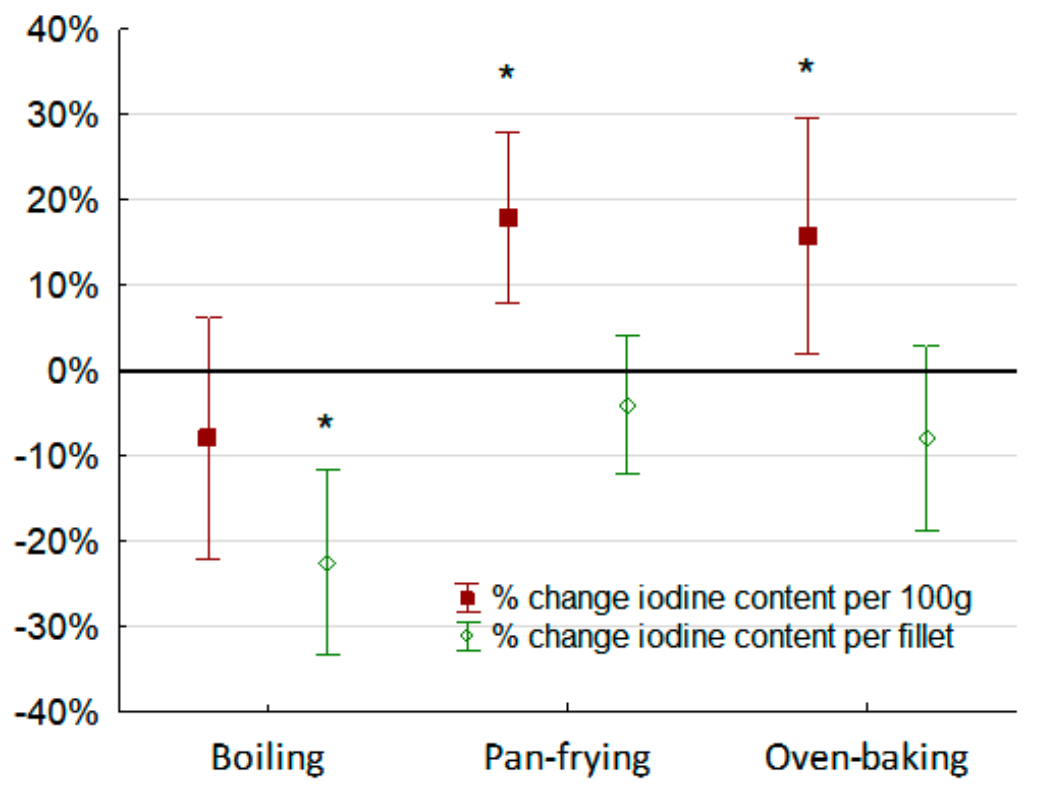

Figure 2. Percentage (\%) change of iodine before and after different cooking methods (wet weight). Red bars show change in iodine content $(\mu \mathrm{g} / 100 \mathrm{~g})$ and green bars show change in total iodine per cod fillet $(\mu \mathrm{g})$. Significant differences within cooking method are indicated by $*(p<0.01)$.

The mercury content before and after boiled $(n=10)$, pan-fried $(n=10)$, and oven-baked $(n=10)$ cod samples are shown in Table 4 . The mean \pm SD mercury per cod fillet in all cod samples $(n=30)$ was $2.8 \pm 1.5 \mu \mathrm{g}$ before and $2.8 \pm 157 \mu \mathrm{g}$ wet weight after the different cooking methods and were not significantly different from each other $(p>0.05)$. The mercury content per $100 \mathrm{~g}$ fillet $(\mu \mathrm{g} / 100 \mathrm{~g})$ increased after the three different cooking methods using wet weight. Since mercury will not dissolve 
in the water phase, we used the dry weight data and found no significant $(p>0.05)$ differences between the different cooking methods.

Table 4. Total mercury per fillet $(\mu \mathrm{g})$ and mercury content per $100 \mathrm{~g}$ fillet $(\mu \mathrm{g} / 100 \mathrm{~g})$ in cod fillets before and after the different cooking methods. Numbers are given as mean \pm SD and (median) wet weight.

\begin{tabular}{ccccc}
\hline Cooking Method & $\begin{array}{c}\text { Mercury/Fillet, } \\
\text { before }(\boldsymbol{\mu g})\end{array}$ & $\begin{array}{c}\text { Mercury/Fillet, } \\
\text { after }(\boldsymbol{\mu g})\end{array}$ & $\begin{array}{c}\text { Mercury Content } \\
\text { before }(\boldsymbol{\mu g} / \mathbf{1 0 0} \mathbf{g})\end{array}$ & $\begin{array}{c}\text { Mercury Content } \\
\text { after }(\boldsymbol{\mu g} / \mathbf{1 0 0} \mathbf{g})\end{array}$ \\
\hline Boiling $(n=10)$ & $2.9 \pm 1.6$ & $2.7 \pm 1.4$ & $2.9 \pm 1.3$ & $3.2 \pm 1.5$ \\
Pan-frying $(n=10)$ & $(2.5)$ & $(2.4)$ & $(2.5)$ & $(2.8)$ \\
Oven-baking $(n=10)$ & $3.3 \pm 1.9$ & $3.5 \pm 1.9$ & $3.3 \pm 1.8$ & $4.3 \pm 2.2$ \\
& $(2.7)$ & $(3.1)$ & $(2.7)$ & $(3.6)$ \\
All $(n=30)$ & $(2.1)$ & $2.2 \pm 0.8$ & $2.3 \pm 0.8$ & $2.7 \pm 1.0$ \\
& $2.9 \pm 1.5$ & $2.8 \pm 1.5$ & $2.8 \pm 1.4$ & $(2.5)$ \\
& $(2.4)$ & $(2.3)$ & $(2.4)$ & $3.4 \pm 1.7$ \\
\hline
\end{tabular}

\section{Discussion}

The present study has assessed the effect of thawing, boiling, pan-frying, and oven-baking on the content of iodine and mercury in Atlantic cod fillets. In general, thawing of frozen cod fillets caused an approximately $12 \%$ loss of iodine to the thawing water. Boiling significantly decreased the total iodine per piece of cod fillet and the corresponding amount of iodine was found in the boiling water. Pan-frying and oven-baking did not cause any significant changes in the iodine per fillet, although iodine content per $100 \mathrm{~g}$ increased due to weight loss of the slices from evaporation of water during cooking. For mercury, we found minimal changes of the different cooking methods.

We found that boiling of the cod fillets significantly decreased the total content of iodine per piece of cod and that this loss was almost equal to the iodine concentration found in the boiling water. Thus, the average iodine loss in $\mu \mathrm{g}$ in the cod fillets can be explained by loss to the boiling water. The iodine content per $100 \mathrm{~g}$ fillet was reduced due to increased dry weight and reduced weight of the cod fillet after boiling. Steaming $\left(105^{\circ} \mathrm{C}\right.$ in aluminum foil for $\left.15 \mathrm{~min}\right)$ has previously been shown to not affect iodine content in hake (Merlucius australis), monkfish (Lophius piscatorius), mackerel (Scomber scombrus), tuna (Katsuonus pelamis), plaice (Pleuronectes platessa), mussel (Mytilus edulis), octopus (Octopus vulgaris), and shrimp (Litopenaeus vannamel) [21]. In the study by Doh et al., 2019, they found more than 60\% loss of iodine after boiling abalone (Haliotis discus hannai) and 32\% reduction after steaming or grilling [22]. Some of the explanation for higher loss of iodine from abalone may be that they are invertebrates, with open circulatory system, which may lead to greater loss of water-soluble components during boiling. Invertebrates also have higher concentrations of osmolytes in the tissues as they are osmoconformers and this may further contribute to greater loss of iodine. Although the loss is different between our study and Doh et al., 2019, it is reasonable that some iodine will be lost during boiling as iodide is reactive with the potential to undergo oxidation and reduction reactions within the food matrix [22]. Even if the iodine loss after boiling was higher per fillet than per $100 \mathrm{~g}$ cod fillet in our study, our results indicate a reduction of iodine in the range of $10-20 \%$.

Most studies have primarily assessed the fate of iodized salt in a variety of foods after different cooking methods [23-26], and there are few studies investigating the effect different cooking- and processing methods may have on iodine content in fish and other seafood. In the study by Longvah et al., 2013 , they reported an average loss of $47 \%$ iodine in different recipes from the Indian kitchen using iodized salt after boiling and the range of loss was from 14 to $88 \%$ [24]. The same study also reported a minor loss of iodine with cooking methods such as steaming, deep frying, and pressure cooking of the different recipes. Loss of iodine from the use of added iodized salt in food/recipes is not exactly comparable to the aim in the present study, but will be relevant when estimating iodine intake from the diet. 
Pan-frying and oven-baking of the cod fillets showed minor changes of the total content of iodine $(\mu \mathrm{g})$ per piece of cod in the present study. As a result that the dry weight percentage increased and the weight of the cod fillets decreased due to evaporation of water, we observed that the iodine content per $100 \mathrm{~g}(\mu \mathrm{g} / 100 \mathrm{~g})$ in wet weight increased with $15-20 \%$ after pan frying or oven baking. We therefore assume that these two cooking methods are better in regard to preserving the iodine content compared to boiling. However, if cod is part of a dish where also the water is consumed (e.g., soup), the iodine loss will be less and comparable to pan-frying and oven-baking.

Different studies investigating mercury in seafood shows that cooking in general tends to increase the wet weight content of mercury in seafood, most likely due to loss of moisture during the cooking process $[12,27,28]$. Our results support these findings regarding mercury since we also observed a minor decrease of the moisture after pan-frying and oven-baking. In a study with Spanish mackerel (Scomberomorus maculatus), cat shark (Scyliorhinus sp.), and red tuna (Thunus thynnus), the dry weight mercury content for all these three fish species were slightly higher after boiling compared to frying and raw fish [29]. In the same study, they found that boiling and frying reduced mercury bioaccessibility by $40 \%$ and $60 \%$, respectively, compared to raw fish mercury bioaccessibility. Bioaccessibility is the proportion of the mercury that potentially reaches the systemic circulation. The mercury bioaccessibility ranged from $10 \%$ in octopus (Octopus vulgaris) to $60 \%$ in monkfish (Lophius piscatorius) [21]. Thus, although the mercury after different cooking methods is almost unchanged in the present study, the estimation of exposure of mercury can probably be overestimated due to a reduced bioaccessibility of the mercury after cooking [21]. However, this was not assessed in this experiment and must be explored further.

As frozen cod were used in the present study, we were able to study if there were any changes of iodine content during thawing. The cod was frozen and thawed twice before we performed the different cooking methods of the portion packed cod. Given an average $12 \%$ loss of iodine due to thawing, the fresh caught cod may therefore originally have had up to a $25 \%$ higher iodine concentration. Using this approach, the iodine content in the fresh caught cod was approximately $100 \mu \mathrm{g} / 100 \mathrm{~g}$ fillet. However, this finding has probably no important relevance for estimating iodine intake from cod, since cod should not be eaten raw due to parasites.

The large variation of iodine between and within fish species, but also in relation to condition factor $\left(100 \times\right.$ weight/lenght $\left.{ }^{3}\right)$, season, and geographical location $[9,15]$, is a challenge when estimating the iodine intake from cod. The reported range of iodine in raw Atlantic cod fillets was 22 to $720 \mu \mathrm{g} / 100 \mathrm{~g}$ $(n=121)$ in the paper by Nerhus et al., 2018 and 18 to $1270 \mu \mathrm{g} / 100 \mathrm{~g}(n=125)$ in the paper by Julshamn et al., 2001 [8]. Atlantic cod is regarded as a fish species relatively low in mercury; however, there are also large intraspecies variations. Still, the mercury content in cod varies less compared with iodine and ranged from 1 to $54 \mu \mathrm{g} / 100 \mathrm{~g}(n=516)$ with a mean of $11 \pm 7 \mu \mathrm{g} / 100 \mathrm{~g}$ in a study from the North Sea and costal Norwegian waters and from 1 to $16 \mu \mathrm{g} / 100 \mathrm{~g}(n=804)$ with a mean of $3.6 \pm 2.3 \mu \mathrm{g} / 100 \mathrm{~g}$ in samples from the Barents Sea [15]. The mercury content in the present study was approximately $3 \mu \mathrm{g} / 100 \mathrm{~g}$ raw fillet.

In the Norwegian FCT [3] boiled (fillet), oven-baked, and pan-fried are given the same value as raw cod $(279 \mu \mathrm{g} / 100 \mathrm{~g})$, while sliced cod has lower value $(194 \mu \mathrm{g} / 100 \mathrm{~g})$. In the INFOODS FCDB, boiled and grilled cod are given values higher than raw as seen in the present study as well, ranging from $280-400 \mu \mathrm{g} / 100 \mathrm{~g}$. In both the INFOODS FCDB [4] and the Norwegian FCT [3], these values are estimated. Our study contributes with novel and new data on the effect of different cooking methods on the iodine level that further can be implemented in FCDBs and FCTs. With the shortage of studies regarding the effect of the cooking process on iodine, we can only speculate and assume that loss of iodine after boiling is most likely the same for other lean fish species.

Representative and reliable analytical food composition data are considered essential for estimating and evaluating the nutrient intake of individuals and population groups. To estimate intake of iodine and mercury exposure, representative and reliable analytical data are essential. Therefore, our study will provide new insights and reliable information that will increase the quality of iodine values after 
different cooking methods of cod fillets in FCDBs and FCTs, and further the quality of data reporting the dietary iodine intake. FCDBs and FTCs would also benefit in including the most important food safety parameters like e.g., mercury. A limitation of our study is the relatively low number of samples for each cooking method and the smaller variation in the iodine content compared to other studies reporting iodine content.

\section{Conclusions}

The present study has determined the effect of thawing and different cooking methods on the content of iodine and mercury in Atlantic cod. Boiling decreased the iodine content per fillet and per $100 \mathrm{~g}$ fillet with approximately $10-20 \%$. Pan-frying and oven-baking caused minor changes in the net iodine content, while content per $100 \mathrm{~g}$ increased due to reduced moisture. For mercury, we found minimal changes of the different cooking methods. Further studies are warranted to better understand the variation in iodine content in different fish species fillets and type of processing should be specified in food composition databases.

Author Contributions: Conceptualization, L.D., A.D., M.W.M. and M.K.; data collection and analysis, L.D., A.D. and S.N.; investigation, L.D., S.N., M.W.M., I.N., L.K.M. and M.K.; writing-original draft preparation, L.D.; writing-review and editing, all authors. All authors have read and agreed to the published version of the manuscript.

Funding: This work was supported by the Institute of Marine Research (IMR), Bergen, Norway.

Acknowledgments: Thanks a lot, to Ingeborg Hollekim Bringslid and Patrick Andre Korneliussen for skillful help during the practical procedure of the experiment. Thanks to Tonja Lill Eidsvik and Berit Solli for technical assistance with the analysis at the laboratory.

Conflicts of Interest: The authors declare no conflict of interest.

\section{Abbreviations}

$\begin{array}{ll}\text { CRM } & \text { Certified Reference Material } \\ \text { DMA-80 } & \text { Direct Mercury Analyzer } \\ \text { FCDB } & \text { Food Composition Databases } \\ \text { FCT } & \text { Food Composition Tables } \\ \text { ICP-MS } & \text { Inductively Coupled Plasma-Mass Spectrometry } \\ \text { IMR } & \text { Institute of Marine Research } \\ \text { INFOODS } & \text { International Network of Food Data Systems } \\ \text { LOD } & \text { Limit of Detection } \\ \text { LOQ } & \text { Limit of Quantification } \\ \text { TMAH } & \text { Tetrametylammounium Hydroxid }\end{array}$

\section{References}

1. Castanheira, I.; Saraiva, M.; Rego, A.; Ollilainen, V. EuroFIR guidelines for assessment of methods of analysis: GAMA. Food Chem. 2016, 193, 82-89. [CrossRef] [PubMed]

2. Erkan, N. Iodine content of cooked and processed fish in Turkey. Int. J. Food Sci. Technol. 2011, 46, 1734-1738. [CrossRef]

3. Norwegian Food Composition Table. Available online: https://www.matvaretabellen.no/?language=en (accessed on 10 November 2020).

4. International Network of Food Data Systems (INFOODS). Available online: http://www.fao.org/infoods/ infoods/tables-and-databases/faoinfoods-databases/en/ (accessed on 10 November 2020).

5. Food and Agriculture Organization of the United Nations. FAO/INFOODS Global Food Composition Database for Fish and Shellfish Version 1.0 - uFiSh1.0. 2006. Available online: http://www.fao.org/3/a-i6655e.pdf (accessed on 10 November 2020).

6. Institute of Marine Research. Seafood data. Available online: https://sjomatdata.hi.no/\#search/ (accessed on 10 November 2020). 
7. Ølmheim, O. Economic and Biological Figures from NORWEGIAN Fisheries-2019; Directorate of Fisheries: Bergen, Norway, 2020; 38p.

8. Julshamn, K.; Dahl, L.; Eckhoff, K. Determination of Iodine in Seafood by Inductively Coupled Plasma/Mass Spectrometry. J. AOAC Int. 2001, 84, 1976-1983. [CrossRef] [PubMed]

9. Nerhus, I.; Markhus, M.W.; Nilsen, B.M.; Øyen, J.; Maage, A.; Ødegård, E.R.; Midtbø, L.K.; Frantzen, S.; Kögel, T.; Graff, I.E.; et al. Iodine content of six fish species, Norwegian dairy products and hen's egg. Food Nutr. Res. 2018, 62. [CrossRef]

10. Zimmerman, M.B.; Boelaert, K. Iodine deficiency and thyroid disorders. Lancet Diabetes Endocrinol. 2015, 3, 286-295. [CrossRef]

11. NNR. Nordic Nutrition Recommendation 2012 Integrating Nutrition and Physical Activity, 5th ed.; Nordic Council of Ministers: Copenhagen, Denmark, 2014. Available online: https://norden.diva-portal.org/smash/get/diva2: 704251/FULLTEXT01.pdf (accessed on 2 October 2020).

12. Bradley, M.A.; Barst, B.D.; Basu, N. A Review of Mercury Bioavailability in Humans and Fish. Int. J. Environ. Res. Public Health 2017, 14, 169. [CrossRef]

13. Azad, A.M.; Frantzen, S.; Bank, M.S.; Nilsen, B.M.; Duinker, A.; Madsen, L.; Maage, A. Effects of geography and species variation on selenium and mercury molar ratios in Northeast Atlantic marine fish communities. Sci. Total. Environ. 2019, 652, 1482-1496. [CrossRef]

14. Sheehan, M.C.; A Burke, T.; Navas-Acien, A.; Breysse, P.N.; Mcgready, J.; A Fox, M. Global methylmercury exposure from seafood consumption and risk of developmental neurotoxicity: A systematic review. Bull. World Health Organ. 2014, 92, 254F-269F. [CrossRef]

15. Julshamn, K.; Duinker, A.; Nilsen, B.M.; Nedreaas, K.; Maage, A. A baseline study of metals in cod (Gadus morhua) from the North Sea and coastal Norwegian waters, with focus on mercury, arsenic, cadmium and lead. Mar. Pollut. Bull. 2013, 72, 264-273. [CrossRef]

16. Nerhus, I.; Odland, M.; Kjellevold, M.; Midtbø, L.K.; Markhus, M.W.; Graff, I.E.; Lie, Ø.; Kvestad, I.; Frøyland, L.; Dahl, L.; et al. Iodine status in Norwegian preschool children and associations with dietary iodine sources: The FINS-KIDS study. Eur. J. Nutr. 2019, 58, 2219-2227. [CrossRef]

17. Aakre, I.; Næss, S.; Kjellevold, M.; Markhus, M.W.; Alvheim, A.R.; Dalane, J.Ø.; Kielland, E.; Dahl, L. New data on nutrient composition in large selection of commercially available seafood products and its impact on micronutrient intake. Food Nutr. Res. 2019, 63. [CrossRef] [PubMed]

18. Næss, S.; Aakre, I.; Lundebye, A.-K.; Ørnsrud, R.; Kjellevold, M.; Markhus, M.W.; Dahl, L. Mercury, lead, arsenic, and cadmium in Norwegian seafood products and consumer exposure. Food Addit. Contam. Part B 2020, 13, 99-106. [CrossRef]

19. Markhus, M.W.; Kvestad, I.; Midtbø, L.K.; Nerhus, I.; Ødegaard, E.R.; Graff, I.E.; Lie, Ø.; Dahl, L.; Hysing, M.; Kjellevold, M. Effects of cod intake in pregnancy on iodine nutrition and infant development: Study protocol for Mommy's Food-a randomized controlled trial. BMC Nutr. 2018, 4, 7-8. [CrossRef] [PubMed]

20. U.S. EPA. EPA Method 7473 (SW-846): Mercury in Solids and Solutions by Thermal Decomposition, Amalgamation, and Atomic Absorption Spectrophotometry. 1998. Available online: https://www.epa.gov/ esam/epa-method-7473-sw-846-mercury-solids-and-solutions-thermal-decomposition-amalgamation-and (accessed on 10 November 2020).

21. Alves, R.N.; Maulvault, A.L.; Barbosa, V.L.; Fernandez, M.; Tediosi, A.; Kotterman, M.; van der Heuvel, F.H.; Robbens, J.; Fernandes, J.; Rasmussen, R.R.; et al. Oral bioaccessibility of toxic and essential elements in raw and cooked commercial seafood species available in European markets. Food Chem. 2018, 267, 15-27. [CrossRef] [PubMed]

22. Doh, H.; Lee, M.H.; Park, H.J. Effect of different cooking methods on the content and bioaccessibility of iodine components in abalone (Haliotis discus hannai). Food Chem. 2019, 301, 125197. [CrossRef] [PubMed]

23. Goindi, G.; Karmarkar, M.G.; Kapil, U.; Jagannathan, J. Estimation of losses of iodine during different cooking procedures. Asia Pac. J. Clin. Nutr. 1995, 4, 225-227. [PubMed]

24. Longvah, T.; Toteja, G.; Upadhyay, A. Iodine content in bread, milk and the retention of inherent iodine in commonly used Indian recipes. Food Chem. 2013, 136, 384-388. [CrossRef]

25. Meinhardt, A.-K.; Müller, A.; Burcza, A.; Greiner, R. Influence of cooking on the iodine content in potatoes, pasta and rice using iodized salt. Food Chem. 2019, 301, 125293. [CrossRef]

26. Rana, R.; Raghuvanshi, R.S. Effect of different cooking methods on iodine losses. J. Food Sci. Technol. 2013, 50, 1212-1216. [CrossRef] 
27. Morgan, J.N.; Berry, M.R.; Graves, R.L. Effects of commonly used cooking practices on total mercury concentration in fish and their impact on exposure assessments. J. Expo. Anal. Environ. Epidemiol. 1997, 7, 119-133.

28. Perelló, G.; Martí-Cid, R.; Llobet, J.M.; Domingo, J.L. Effects of Various Cooking Processes on the Concentrations of Arsenic, Cadmium, Mercury, and Lead in Foods. J. Agric. Food Chem. 2008, 56, 11262-11269. [CrossRef] [PubMed]

29. Ouédraogo, O.; Amyot, M. Effects of various cooking methods and food components on bioaccessibility of mercury from fish. Environ. Res. 2011, 111, 1064-1069. [CrossRef] [PubMed]

Publisher's Note: MDPI stays neutral with regard to jurisdictional claims in published maps and institutional affiliations.

(C) 2020 by the authors. Licensee MDPI, Basel, Switzerland. This article is an open access article distributed under the terms and conditions of the Creative Commons Attribution (CC BY) license (http://creativecommons.org/licenses/by/4.0/). 